\title{
Mutations within FGFR1 are associated with superior outcome in a series of 83 diffuse midline gliomas with H3F3A K27M mutations
}

\author{
Ulrich Schüller ${ }^{1,2,3}$ (D) Peter Iglauer ${ }^{4} \cdot$ Mario M. Dorostkar ${ }^{5,6} \cdot$ Christian Mawrin $^{7} \cdot$ Jochen Herms $^{5,6} \cdot$ Armin Giese $^{5}$. \\ Markus Glatzel ${ }^{1}$. Julia E. Neumann ${ }^{1}$ (1)
}

Received: 14 October 2020 / Revised: 21 December 2020 / Accepted: 22 December 2020 / Published online: 12 January 2021

(c) The Author(s) 2021

Diffuse midline glioma (DMG), H3 K27M mutant (WHO grade IV) is listed as a separate CNS tumor entity since 2016 [5], after large sequencing efforts had discovered H3 K27M mutations frequently appearing in gliomas located in midline structures [11]. Over time, we and others have observed single cases of DMG with concomitant mutations within FGFRI or BRAF [1, 2, 4, 6, 7, 9, 10, 12-14]. FGFRI and $B R A F$ mutations are typical hallmarks of low grade glioma, such as pilocytic astrocytoma, ganglioglioma, or dysembryoplastic neuroepithelial tumor $[3,8]$. So, the parallel occurrence of $\mathrm{H} 3$ and $F G F R 1 / B R A F$ mutations within a single tumor may complicate the diagnostic decision towards a low grade or a high grade glioma. This dilemma, which has direct clinical implications, is particularly evident, if only small biopsies are taken and low-grade histology may not

Supplementary Information The online version of this article (https://doi.org/10.1007/s00401-020-02259-y).

Ulrich Schüller

u.schueller@uke.de

$\triangle$ Julia E. Neumann

ju.neumann@uke.de

1 Institute of Neuropathology, University Medical Center Hamburg-Eppendorf, Hamburg, Germany

2 Department of Pediatric Hematology and Oncology, University Medical Center Hamburg-Eppendorf, Hamburg, Germany

3 Research Institute Children's Cancer Center Hamburg, Hamburg, Germany

4 Institute of Pathology, University Medical Center Hamburg-Eppendorf, Hamburg, Germany

5 Center for Neuropathology, Ludwig-Maximilians-University, Munich, Germany

6 German Center for Neurodegenerative Diseases, Munich, Germany

7 Institute of Neuropathology, University Hospital Magdeburg, Magdeburg, Germany be respresentative and hence may not mirror the biology of the neoplasm. On the other hand, the presence of a MAPK pathway alteration, such as $F G F R I$ or $B R A F$ mutations, may open up additional possibilities of targeted therapies, independent of the tumor classification.

In order to learn more about the frequency and impact on such mutations, we analyzed a series of $83 \mathrm{DMG}, H 3 F 3 \mathrm{~A}$ K27M mutant. Details on clinical characteristics of patients are listed in Fig. 1a and Supplementary Table 1, online resource. One case (1.2\%) displayed a $B R A F$ (p.V600E) mutation and $9 / 83$ cases (10.8\%) showed FGFRl mutations (p.K656E or p.N546K). Mutations within NF1, TP53, and $A T R X$ were detected in $31.8 \%, 51.4 \%$, and $35.2 \%$, respectively. TP53 mutations were significantly associated with $F G F R 1$ wild type status (FGFRl WT, $p=0.009, X^{2}$-test, Supplementary Fig. 1a, online resource).

Similar to FGFRI WT cases, cases with additional FGFR1 mutation displayed features of a diffusely growing glioma with increased cellularity and signs of anaplasia, such as increased cell pleomorphism, mitoses, or vessel proliferation (Fig. 1b-e). Furthermore, all analyzed FGFRI MU cases (and the BRAF MU case) matched to the methylation class"DMG, H3 K27M mutant" (Supplementary Fig. 1b, online resource, Fig. 1f, Supplementary Table 1, online resource).

Higher age ( $\geq 18$ years), supratentorial tumor localization and FGFRI MU status were associated with a significantly better prognosis of patients $(p=0.038, p=0.034$, and $p=0.023$, Fig. $1 \mathrm{~g}$ and Supplementary Fig. 2a, b, online resource). In contrast, TP53 MU status was associated with a significantly worse prognosis of patients ( $p=0.002$, Supplementary Fig. 2c, online resource). Including the latter factors in a multivariate cox regression analyses showed localization and TP53 status as significant variables (Supplementary Fig. 2d, online resource). FGFRI and TP53 mutations occurred almost mutually exclusive and hence did not represent independent variables (see also Supplementary Fig. 1a, 

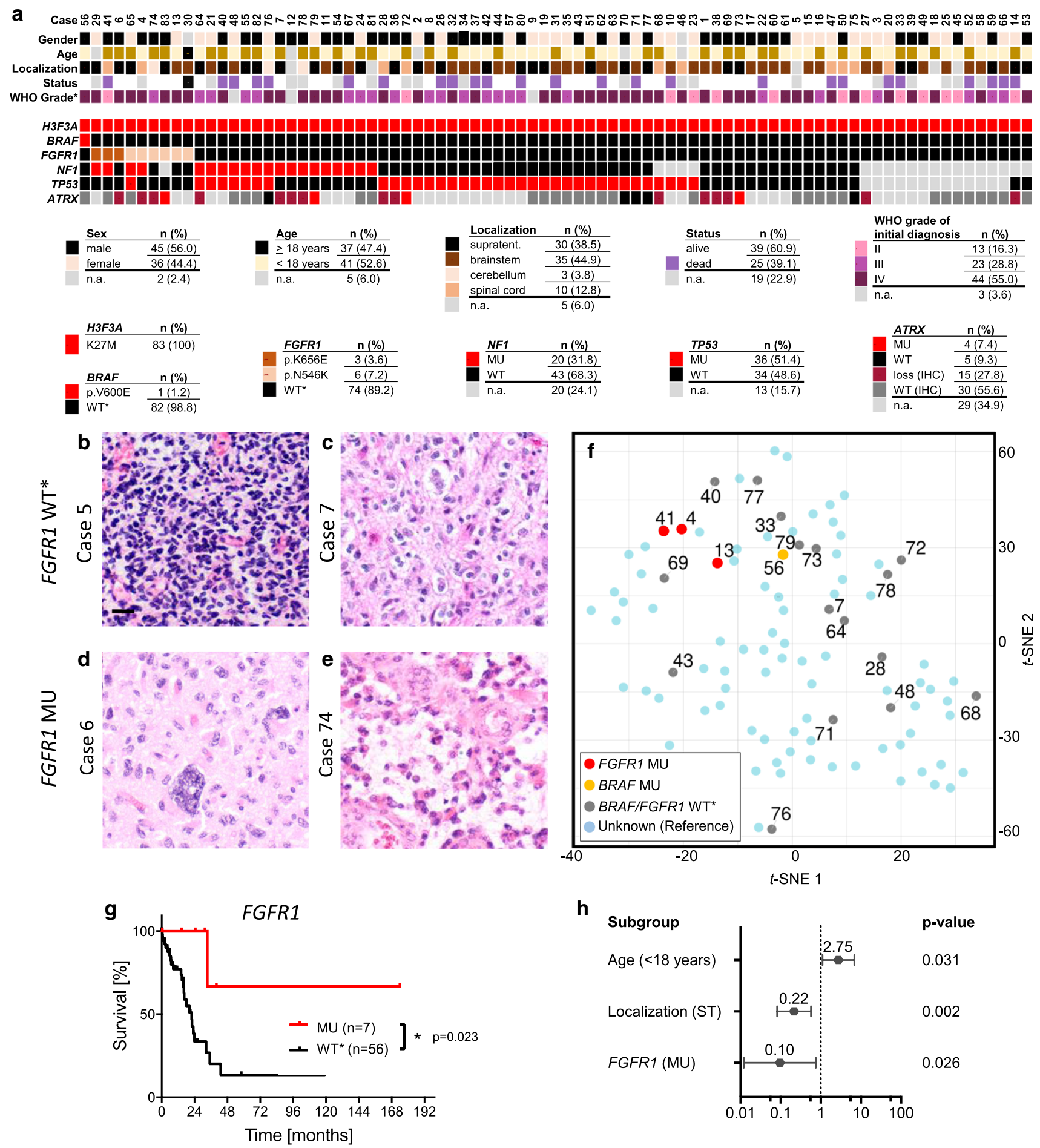

Fig. 1 Clinical, histological, and molecular parameters of $H 3 F 3 A$ K27M mutated DMG with and without additional mutations in FGFR1. a Overview on all 83 analyzed cases with $12 \%$ of cases harboring BRAF or FGFRl hotspot mutations. Percentages of characteristics refer to cases with known attribute only. Representative images of FGFRI WT $(\mathbf{b}, \mathbf{c})$ and MU cases $(\mathbf{d}, \mathbf{e})$ demonstrate comparable histomorphology in both groups. T-SNE analysis of DMG reveals
$F G F R 1$ and $B R A F$ MU cases to harbor similar DNA methylation profiles as FGFR1 and BRAF WT cases (f). FGFR1 MU cases showed a significantly better prognosis than FGFRl WT cases $(p=0.023$, g), and multivariate analyses confirmed significance of FGFR1 status independent of age and localization. $\mathrm{WT}^{*}=$ wild type for respective hotspot, $\mathrm{MU}=$ mutant, $\mathrm{n} . \mathrm{a} .=$ not available, $* \mathrm{WHO}$ grade of initial diagnosis 
online resource). Thus, we performed a multivariate analysis including the independent variables age, localization, and FGFRl status only (Fig. 1h). In this context, FGFRl MU status was significantly associated with a better overall survival, independently of patient age, and tumor localization $(p=0.026)$. Interestingly, the single patient (\#56) with an accompanying BRAF p.V600E mutation remained alive at 24.5 months after initial diagnosis. However, the prognosis for such diffuse midline gliomas with dual H3F3A p.K27M and BRAF p.V600E mutations remains to be defined.

Together, our results suggest that RAS-MAPK-pathway signaling might play an important role in DMG with implications for diagnosis, prognosis, and therapy of respective patients.

Acknowledgements We thank Anne Reichstein, Michael Ruiter, Janina Mielke, Celina Soltwedel, Matthias Dottermusch, and Michael Spohn for technical support. J.N. was supported by the Else-Kröner Fresenius Stiftung, the UKE Nachwuchsförderung and the Emmy-Noether program of the DFG. U.S. received further funding from the Werner Otto Stiftung and the Fördergemeinschaft Kinderkrebszentrum Hamburg.

Funding Open Access funding enabled and organized by Projekt DEAL.

Data availability Global DNA Methylation data have been deposited under GEO accession number GSE161944.

Open Access This article is licensed under a Creative Commons Attribution 4.0 International License, which permits use, sharing, adaptation, distribution and reproduction in any medium or format, as long as you give appropriate credit to the original author(s) and the source, provide a link to the Creative Commons licence, and indicate if changes were made. The images or other third party material in this article are included in the article's Creative Commons licence, unless indicated otherwise in a credit line to the material. If material is not included in the article's Creative Commons licence and your intended use is not permitted by statutory regulation or exceeds the permitted use, you will need to obtain permission directly from the copyright holder. To view a copy of this licence, visit http://creativecommons.org/licenses/by/4.0/.

\section{References}

1. Dufour C, Perbet R, Leblond P, Vasseur R, Stechly L, Pierache A et al (2020) Identification of prognostic markers in diffuse midline gliomas H3K27M-mutant. Brain Pathol 30:179-190

2. Fontebasso AM, Papillon-Cavanagh S, Schwartzentruber J, Nikbakht H, Gerges N, Fiset PO et al (2014) Recurrent somatic mutations in ACVR1 in pediatric midline high-grade astrocytoma. Nat Genet 46:462-466
3. Jones D, Huttler B, Jäger N, Korshunov A, Kool M, Warnatz HJ et al (2013) Recurrent somatic alterations of FGFR1 and NTRK2 in pilocytic astrocytoma. Nat Genet 45:927-932

4. Lopez GY, Oberheim Bush NA, Phillips JJ, Bouffard JP, Moshel YA, Jaeckle K et al (2017) Diffuse midline gliomas with subclonal H3F3A K27M mutation and mosaic H3.3 K27M mutant protein expression. Acta Neuropathol 134:961-963

5. Louis D, Ohgaki H, Wiestler OD, Cavenee WK, Ellison DW, Figarella-Branger et al (2016) WHO classification of tumours of the central nervous system (Revised 4th edition). Lyon, IARC

6. Mackay A, Burford A, Carvalho D, Izquierdo E, Fazal-Salom J, Taylor KR et al (2017) Integrated molecular meta-analysis of 1000 pediatric high-grade and diffuse intrinsic pontine glioma. Cancer Cell 32:520-537

7. Nguyen C, Colin I, Nanni-Metellus L, Padovani L, Maurage CA, Varlet P et al (2015) Evidence for BRAF V600E and H3F3A $\mathrm{K} 27 \mathrm{M}$ double mutations in paediatric glial and glioneuronal tumours. Neuropathol Appl Neurobiol 41:403-408

8. Pages M, Beccaria K, Boddaert N, Saffroy R, Besnard A, Castel D et al (2018) Co-occurrence of histone H3 K27M and BRAF V600E mutations in paediatric midline grade I ganglioglioma. Brain Pathol 28:103-111

9. Ryall S, Krishnatry R, Arnoldo A, Buczkowicz P, Mistry M, Siddaway $R$ et al (2016) Targeted detection of genetic alterations reveal the prognostic impact of H3K27M and MAPK pathway aberrations in paediatric thalamic glioma. Acta Neuropathol Commun 4:93

10. Schulte JD, Buerki RA, La Pointe SL, Molinaro AM, Zhang Y, Villanueva-Meyer JE et al (2020) Clinical, radiologic, and genetic characteristics of histone H3 K27M-mutant diffuse midline glioma in adults. Neuro-Oncol Adv 2:vdaa142. https://doi.org/10.1093/ noajnl/vdaa142

11. Schwarzentruber J, Korshunov A, Liu XY, Jones DT, Pfaff E, Jacob K et al (2012) Driver mutations in histone H3.3 and chromatin remodelling genes in paediatric glioblastoma. Nature 482:226-231

12. Sloan EA, Cooney T, Oberheim Bush NA, Buerki R, Taylor J, Clarke JL et al (2019) Recurrent non-canonical histone H3 mutations in spinal cord diffuse gliomas. Acta Neuropathol 138:877-881

13. Solomon DA, Wood MD, Tihan T, Bollen AW, Gupta N, Phillips JJ et al (2016) Diffuse midline gliomas with histone H3-K27M mutation: a series of 47 cases assessing the spectrum of morphologic variation and associated genetic alterations. Brain Pathol 2016(26):569-580

14. Vettermann F, Neumann J, Suchorska B, Bartenstein P, Giese A, Dorostkar MM et al (2017) K27M midline gliomas display malignant progression by imaging and histology. Neuropathol Appl Neurobiol 43:458-462

Publisher's Note Springer Nature remains neutral with regard to jurisdictional claims in published maps and institutional affiliations. 